Open Access

\title{
Clinical characteristics and risk factors of enterococcal infections in Nagasaki, Japan: a retrospective study
}

Toshiki Kajihara ${ }^{1,4}$, Shigeki Nakamura ${ }^{1,5^{*}}$, Naoki Imanaga ${ }^{1}$, Kazuhiro Oshima ${ }^{2}$, Takahiro Takazono ${ }^{1}$, Taiga Miyazaki ${ }^{1}$, Koichi Izumikawa ${ }^{2}$, Katsunori Yanagihara ${ }^{3}$, Nobuoki Kohno ${ }^{4}$ and Shigeru Kohno ${ }^{1}$

\begin{abstract}
Background: Enterococcus spp. are particularly important etiological agents of nosocomial infections. However, the clinical characteristics of and risk factors for enterococcal infections in clinical settings are poorly understood.

Methods: The sample included patients with Enterococcus spp. infections detected from clinical samples at Nagasaki University Hospital between 2010 and 2011 and patients with enterococcal colonization (control patients). In this retrospective study, the risk factors for enterococcal infections were analyzed by comparing infected and control patients via multivariate logistic regression.

Results: A total of 182 infected (mean age, $64.6 \pm 18.2$ years; 114 men) and 358 control patients (patients with enterococcal colonization) (mean age, $61.6 \pm 22.4$ years; 183 men) were included. Enterococcal infections were classified as intraperitoneal $(n=87)$, urinary tract $(n=28)$, or bloodstream $(n=20)$ infections. Cancer and hematological malignancies were the most common comorbidities in enterococcal infections. Carbapenem and vancomycin were administered to $43.8 \%$ and $57.9 \%$ of patients infected with Enterococcus faecalis and Enterococcus faecium, respectively. No vancomycin-resistant enterococci were isolated. Multivariate analysis identified abdominal surgery (odds ratio [OR], 2.233; $95 \%$ confidence interval [Cl], 1.529-3.261; $p \leq 0.001$ ), structural abnormalities of the urinary tract $(\mathrm{OR}, 2.086 ; 95 \% \mathrm{Cl}, 1.088-4.000 ; p=0.027)$, male sex (OR, 1.504; $95 \% \mathrm{Cl}, 1.032-2.190 ; p=0.033)$, and hypoalbuminemia $(\mathrm{OR}, 0.731 ; 95 \% \mathrm{Cl}, 0.555-0.963 ; p=0.026)$ as independent risk factors for enterococcal infections. Multivariate analysis showed abdominal surgery (OR, 2.263; $95 \% \mathrm{Cl}, 1.464-3.498 ; p \leq 0.001)$, structural abnormalities of the urinary tract (OR, 2.634; $95 \% \mathrm{Cl}, 1.194-5.362 ; p=0.008$ ), and hypoalbuminemia (OR, $0.668 ; 95 \% \mathrm{Cl}, 0.490-0.911 ; p=0.011$ ) were independent risk factors for $E$. faecalis infection. Finally, immunosuppressive agent use $(\mathrm{OR}, 3.837 ; 95 \% \mathrm{Cl}, 1.397-10.541$; $p=0.009)$ and in situ device use $(\mathrm{OR}, 3.807 ; 95 \% \mathrm{Cl}, 1.180-12.276 ; p=0.025)$ were independent risk factors for $E$. faecium infection.
\end{abstract}

Conclusions: These findings might inform early initiation of antimicrobial agents to improve clinical success.

Keywords: Enterococcal infection, Risk factor, Retrospective study, Multivariate analysis

\footnotetext{
*Correspondence: shigekinak@nih.go.jp

'Department of Respiratory Diseases, Nagasaki University Graduate School of

Biomedical Sciences, Nagasaki, Japan

${ }^{5}$ Department of Chemotherapy and Mycoses, National Institute of Infectious

Diseases, 1-23-1 Toyama, Shinjuku-ku, Tokyo 162-8640, Japan

Full list of author information is available at the end of the article
} 


\section{Background}

Enterococci are gram-positive, catalase-negative, and non-spore-forming facultative anaerobic bacteria. Enterococci are generally commensal and may aid with digestion and other gut metabolic pathways [1, 2]. The two most common species responsible for enterococcal infections in humans are Enterococcus faecalis and Enterococcus faecium. Some Enterococcus species are used in probiotics to treat diarrhea and improve host immunity [3]. While most Enterococcus species are commensal organisms, E. faecalis and E. faecium have become particularly important etiological agents of nosocomial infections [4, 5]; both can survive in hospital environments and colonize patients, causing infections such as urinary tract infections, hepatobiliary sepsis, endocarditis, surgical wound infections, bacteremia, and neonatal sepsis. Previous reports have shown that pharyngeal or intestinal colonization of enterococci are risk factors for enterococcal bacteremia, which is associated with increased mortality, particularly in immunocompromised patients [6-8]. Enterococci, one of the most common nosocomial pathogens, incur a high mortality rate. The increasing use of antineoplastic, biological, and other immunosuppressive agents is one reason enterococcal infections have become a major cause of nosocomial infections $[9,10]$. This study aimed to describe the epidemiology clinical characteristics of and risk factors for enterococcal infections.

\section{Methods}

\section{Study design}

We performed a retrospective study of patients in whom enterococci were detected in clinical samples between January 1, 2010, and December 31, 2011, at Nagasaki University Hospital, an 862-bed tertiary care and teaching hospital in Nagasaki, Japan, to identify the risk factors for enterococci infection. Medical records were reviewed for all patients with samples that were culturepositive for enterococcal organisms. A total of 571 cases positive for Enterococcus spp (540 inpatients, 31 outpatients) and 583 isolates were analyzed, including 12 duplicated cases (in which the enterococci were reisolated $>3$ months after the first isolation, or multiple enterococci were isolated from a patient). This retrospective study, including the analysis and release of clinical data, was approved by the Ethical Committee of Nagasaki University Hospital.

\section{Enterococcal infection criteria}

Enterococcal infections were identified on the basis of clinical symptoms (temperature $>37.5{ }^{\circ} \mathrm{C}$ and organspecific symptoms), laboratory data (white blood cell count $>9100 / \mathrm{mm}^{3}$ and C-reactive protein $>0.17 \mathrm{mg} / \mathrm{dL}$ ), and bacteriological tests (monomicrobial culture or the same organisms isolated from two organs).
Microorganisms were considered the causative pathogens of cellulitis or cutaneous abscesses when they were cultured from abscess fluid, tissue specimens, or blood. Those who did not present with distinctive symptoms of infection but in whom enterococci had been detected were considered to be uninfected control patients (colonized patients).

\section{Microbiological methods}

Antimicrobial resistance to ampicillin, vancomycin, linezolid, imipenem, levofloxacin, and teicoplanin was detected by measuring minimum inhibitory concentrations using the PMIC-85 test panel for gram-positive bacteria (BD Diagnosis, Sparks, MD, USA) on a BD PHOENIX microbiology system (Becton, Dickinson and Company, NJ, USA). Categorical interpretations were assigned according to Clinical Laboratory Standards Institute recommendations [11].

\section{Statistical analysis}

Data were analyzed by Pearson's $\chi^{2}$ test or Fisher's exact test when the expected count in any category was $>5$, with Bonferroni post-hoc tests. Continuous nonnormally distributed variables were analyzed by the Mann-Whitney $U$-test. Multivariate logistic regression analysis with forward stepwise selection was performed to estimate the adjusted odds ratios (ORs) and $95 \%$ confidence intervals (CIs) of the variables to determine the potential risk factors for infection.

The Hosmer-Lemeshow test was performed as a measure of goodness of fit. The level of significance was set at $p<0.05$. All statistical analyses were performed using IBM SPSS for Windows version 20.0 (IBM Corp., Armonk, NY, USA).

\section{Results}

\section{Study population and patient characteristics}

The epidemiological variables, infection types, antimicrobial therapies, and culture-positive specimens from 583 Enterococcus spp. case isolates are summarized in Table 1. These corresponded to 182 infected patients (33.7 \%), including 74 (40.7 \%) intra-peritoneal infections, 13 (7.1 \%) intra-peritoneal infections after liver transplantation, and 29 (15.9\%) urinary tract infections; moreover, enterococci colonization was noted in 358 hospitalized patients. In intraperitoneal infections after liver transplantation, the number of E. faecium infections was significantly greater than that of $E$. faecalis infections $(p<0.001)$. On the other hand, in urinary tract infections, the number of $E$. faecalis infections was significantly greater than that of E. faecium infections $(p=0.016)$. Enterococcus spp. were identified from urine $(n=32 ; 17.6 \%)$, abscess discharge $(n=45 ; 24.7 \%)$, and blood $(n=37$; $20.3 \%)$. Abscess discharge was the most common $E$. 
Table 1 Epidemiological variables and infection types

\begin{tabular}{|c|c|c|c|}
\hline & Total $n=182$ & E. faecalis $n=144$ & E. faecium $n=38$ \\
\hline Age, mean (SD), years & $64.6(18.2)$ & $65.0(19.3)$ & $64.8(13.5)$ \\
\hline Male sex $n,(\%)$ & $114(62.6)$ & $89(61.8)$ & $25(65.8)$ \\
\hline \multicolumn{4}{|l|}{ Type of infection $n,(\%)$} \\
\hline Intra-peritoneal infections & $74(40.7)$ & $59(41.0)$ & $15(39.5)$ \\
\hline Intra-peritoneal infections after liver transplantation & $13(7.1)$ & $4(2.8)$ & $9(23.7)$ \\
\hline Urinary tract infections & $29(15.9)$ & $29(20.1)$ & $0(0.0)$ \\
\hline Febrile neutropenia & $16(8.8)$ & $11(7.6)$ & $5(13.2)$ \\
\hline Bone and soft-tissue infections & $17(9.3)$ & $14(9.7)$ & $3(7.9)$ \\
\hline Blood stream infections & $20(11.0)$ & $15(10.4)$ & $5(13.2)$ \\
\hline Pulmonary infections & $10(5.5)$ & $10(6.9)$ & $0(0.0)$ \\
\hline Vascular grafts infections & $3(1.6)$ & $2(1.4)$ & $1(2.6)$ \\
\hline \multicolumn{4}{|l|}{ Comorbidity n, (\%) } \\
\hline Cancer and hematologic malignancy & $65(35.7)$ & $57(39.6)$ & $8(21.1)$ \\
\hline Hematologic malignancy & $22(12.1)$ & $14(9.7)$ & $8(21.1)$ \\
\hline Solid organ transplantation & 19 (10.4) & $10(6.9)$ & $9(23.7)$ \\
\hline Bone marrow and stem cell transplantation & $9(4.9)$ & $3(2.1)$ & $6(15.8)$ \\
\hline Diabetes mellitus & $14(7.7)$ & $12(8.3)$ & $2(5.3)$ \\
\hline Collagen vascular disease & $12(6.6)$ & $9(6.3)$ & $3(7.9)$ \\
\hline Chronic kidney disease & $53(29.1)$ & $40(27.8)$ & $13(34.2)$ \\
\hline Structural abnormality of urinary tract & $22(12.1)$ & $21(14.6)$ & $1(2.6)$ \\
\hline Hemodialysis & $12(6.6)$ & $10(6.9)$ & $2(5.3)$ \\
\hline \multicolumn{4}{|l|}{ Antimicrobial therapy $n,(\%)$} \\
\hline Vancomycin & $48(26.4)$ & $26(18.1)$ & $22(57.9)$ \\
\hline Linezolid & $13(7.1)$ & $3(2.1)$ & $8(21.1)$ \\
\hline Teicoplanin & $14(7.7)$ & $6(4.2)$ & $8(21.1)$ \\
\hline Meropenem & $37(20.3)$ & $37(25.7)$ & $0(0.0)$ \\
\hline Imipenem/cilastatin & $15(8.2)$ & $15(10.4)$ & $0(0.0)$ \\
\hline Biapenem & $2(1.1)$ & $2(1.4)$ & $0(0.0)$ \\
\hline Doripenem & $9(4.9)$ & $9(6.3)$ & $0(0.0)$ \\
\hline Piperacillin & $10(5.5)$ & $10(6.9)$ & $0(0.0)$ \\
\hline Tazobactam/piperacillin & $18(9.9)$ & $18(12.5)$ & $0(0.0)$ \\
\hline Ampicillin & $2(1.1)$ & $2(1.4)$ & $0(0.0)$ \\
\hline Sulbactam/ampicillin & $6(3.3)$ & $6(4.2)$ & $0(0.0)$ \\
\hline Levofloxacin & $21(11.5)$ & $21(14.6)$ & $0(0.0)$ \\
\hline Ciprofloxacin & $3(1.6)$ & $3(2.1)$ & $0(0.0)$ \\
\hline Tosufloxacin & $1(0.5)$ & $1(0.7)$ & $0(0.0)$ \\
\hline Combination therapy & $18(9.9)$ & $18(12.5)$ & $0(0.0)$ \\
\hline \multicolumn{4}{|l|}{ Culture-positive specimens $n,(\%)$} \\
\hline Urine & $32(17.6)$ & $27(18.8)$ & $1(2.6)$ \\
\hline Sputum & $9(4.9)$ & $9(6.3)$ & $0(0.0)$ \\
\hline Blood & $37(20.3)$ & $25(17.4)$ & $6(15.8)$ \\
\hline Peritoneal fluid & $32(17.6)$ & $24(16.7)$ & $8(21.1)$ \\
\hline Pleural fluid & $1(0.5)$ & $1(0.7)$ & $0(0.0)$ \\
\hline Bile & $16(8.8)$ & $10(6.9)$ & $6(15.8)$ \\
\hline
\end{tabular}


Table 1 Epidemiological variables and infection types (Continued)

\begin{tabular}{|c|c|c|c|}
\hline Discharge from abscess & $45(24.7)$ & $37(25.7)$ & $8(21.1)$ \\
\hline Central venous catheter tip & $4(2.2)$ & $4(2.8)$ & $0(0.0)$ \\
\hline Throat swab & $5(2.7)$ & $4(2.8)$ & $1(2.6)$ \\
\hline Vascular graft & $3(1.6)$ & $2(1.4)$ & $1(2.6)$ \\
\hline Polymicrobial culture & $83(45.6)$ & $70(48.6)$ & $13(34.2)$ \\
\hline
\end{tabular}

faecalis culture-positive specimen type, occurring in 38 (25.7 \%) infected patients. Peritoneal fluid and abscess discharge were the most common E. faecium culture-positive specimen types, with eight (21.1\%) infected patients.

The overall mean \pm SD age of the patients was $64.6 \pm$ 18.2 years, and 114 patients $(62.8 \%)$ were men. Enterococcal infections were most frequently found in patients with cancer and hematologic malignancy (65 patients; $35.7 \%)$, structural abnormalities of the urinary tract (22 patients; $12.1 \%$ ), and solid organ transplant (19 patients; $10.4 \%)$. Cancer and hematologic malignancies (39.6\%) and structural abnormalities (14.6\%) were most common in patients with E. faecalis infections. Meanwhile, solid organ transplantation (23.7\%) and hematologic malignancy $(21.1 \%)$ were most common in patients with E. faecium infections. Compared with E. faecalis, bone marrow and stem cell transplantation were significantly common in E. faecium infections $(p=0.027)$.

Meropenem was the most commonly prescribed antibiotic for $E$. faecalis $(n=37,25.7 \%)$. Among the patients infected with $E$. faecalis, 18 (12.5\%) received combination therapies consisting of anti-MRSA(Methicillin-resistant Staphylococcus aureus) agents and other antibiotics. Vancomycin was the most commonly prescribed antibiotic for $E$. faecium infections $(n=22,57.9 \%)$.

\section{Antimicrobial susceptibilities of 583 enterococcal strains}

Antimicrobial susceptibility was determined for the 583 isolates. Amoxicillin resistance was observed in $1.1 \%$ of E. faecalis and $90.8 \%$ of E. faecium isolates. In this study, no vancomycin-resistant enterococci were isolated, identical to results of a previous Japanese report [12]. Imipenem resistance was found in $0.9 \%$ of $E$. faecalis and $92.4 \%$ of E. faecium isolates. Levofloxacin resistance was found in $19.9 \%$ of E. faecalis and $96.9 \%$ of E. faecium isolates. Only one E. faecium isolate had teicoplanin resistance. There were no linezolid-resistant enterococci among the 550 enterococcal isolates.

\section{Risk factors for Enterococcus spp. infection}

A total of 182 infected patients and 358 colonized control patients were compared to determine the risk factors for Enterococcus spp. infection (Table 2). In multivariate analysis, abdominal surgery was the strongest risk factor for enterococcal infection (adjusted OR, 2.233; $95 \% \mathrm{CI}$, 1.529-3.261; $p \leq 0.001)$. Other significant risk factors for infection were structural abnormalities of the urinary tract (adjusted OR, 2.086; $95 \% \mathrm{CI}, 1.088-4.000 ; p=$ 0.027), male sex (adjusted OR, 1.504; 95 \% CI, 1.0322.190; $p=0.033$ ), and hypoalbuminemia (adjusted OR, 0.731; 95 \% CI, 0.555-0.963; $p=0.026)$.

\section{Risk factors for $E$. faecalis infection}

A total of 144 infected and 275 control patients were compared to determine the risk factors for E. faecalis infection (Table 2). Structural abnormalities of the urinary tract conferred the highest risk of $E$. faecalis infection (adjusted OR, 2.634; $95 \%$ CI, 1.294-5.362; $p=0.008$ ) on multivariate analysis. Other significant risk factors were abdominal surgery (adjusted OR, 2.263; 95 \% CI, 1.4643.498; $p \leq 0.001$ ) and hypoalbuminemia (adjusted OR, 0.668; 95 \% CI, 0.490-0.911; $p=0.011$ ).

\section{Risk factors for $E$. faecium infection}

A total of 38 infected patients and 83 control patients were compared to determine the risk factors for $E$. faecium infection (Table 2). Immunosuppressive agent use (adjusted OR, 3.837; $95 \% \mathrm{CI}, 1.397-10.541 ; p=0.017$ ) and in situ device use (OR, 3.807; $95 \%$ CI, 1.18012.276 ; $p=0.025$ ) were significant risk factors for $E$. faecium infection.

\section{Discussion}

This retrospective study analyzed the epidemiology, characteristics, and risk factors for vancomycin-susceptible enterococcal (VSE) infections compared with colonized control patients on the basis of medical records.

In the United States, enterococci are recognized as important causative pathogens of catheter-related bloodstream infections, urinary tract infections, and cellulitis $[2,9,10]$.

The independent risk factors for vancomycin-resistant enterococcal (VRE) infection were reported previously. Kim et al. compared the VRE "infected" and "colonized" groups and reported combined infection with bacteria other than VRE, presence of a hemodialysis catheter, and duration of vancomycin use were the independent risk factors for VRE infection [13]. Olivgeris et al. reported that cortisone use, third- or fourth-generation cephalosporins, enteral nutrition, and VRE colonization were the risk factors for developing enterococcal infection in critical ill patients [14]. Zaas et al. reported that 
Table 2 Risk factors for enterococcal infection

\begin{tabular}{|c|c|c|c|c|c|c|c|c|c|c|c|c|c|c|c|}
\hline & \multicolumn{5}{|c|}{ Enterococcal infections } & \multicolumn{5}{|c|}{ Enterococcus faecalis infections } & \multicolumn{5}{|c|}{ Enterococcus faecium infections } \\
\hline & \multirow{2}{*}{$\begin{array}{l}\text { Infections } \\
n=182\end{array}$} & \multirow{2}{*}{$\begin{array}{l}\text { Controls } \\
n=358\end{array}$} & \multirow{2}{*}{$\begin{array}{l}\text { Univariate } \\
p \text { value }\end{array}$} & \multicolumn{2}{|l|}{ Multivariate } & \multirow{2}{*}{$\begin{array}{l}\text { Infections } \\
n=144\end{array}$} & \multirow{2}{*}{$\begin{array}{l}\text { Controls } \\
n=275\end{array}$} & \multirow{2}{*}{$\begin{array}{l}\text { Univariate } \\
p \text { value }\end{array}$} & \multicolumn{2}{|l|}{ Multivariate } & \multirow{2}{*}{$\begin{array}{l}\text { Infections } \\
n=38\end{array}$} & \multirow{2}{*}{$\begin{array}{l}\text { Controls } \\
n=83\end{array}$} & \multirow{2}{*}{$\begin{array}{l}\text { Univariate } \\
p \text { value }\end{array}$} & \multicolumn{2}{|l|}{ Multivariate } \\
\hline & & & & $\begin{array}{l}\text { Adjusted OR } \\
(95 \% \mathrm{Cl})\end{array}$ & $p$ value & & & & $\begin{array}{l}\text { Adjusted OR } \\
(95 \% \mathrm{Cl})\end{array}$ & $p$ value & & & & $\begin{array}{l}\text { Adjusted OR } \\
(95 \% \mathrm{Cl})\end{array}$ & $p$ value \\
\hline Age, years, mean (SD) & $\begin{array}{l}64.6 \\
(18.2)\end{array}$ & $61.6(22.4)$ & 0.458 & - & - & $\begin{array}{l}65.0 \\
(19.3)\end{array}$ & $\begin{array}{l}60.7 \\
(23.0)\end{array}$ & 0.187 & - & - & $64.8(13.5)$ & $\begin{array}{l}64.7 \\
(20.1)\end{array}$ & 0.351 & - & - \\
\hline Sex (male), $n$ (\%) & $114(62.6)$ & $183(51.1)$ & 0.011 & $\begin{array}{l}1.504 \\
(1.032-2.190)\end{array}$ & 0.033 & $89(61.8)$ & $\begin{array}{l}142 \\
(51.6)\end{array}$ & 0.047 & - & - & $25(65.8)$ & $41(49.4)$ & 0.094 & - & - \\
\hline \multicolumn{16}{|l|}{ Comorbidities, n (\%) } \\
\hline Diabetes mellitus & $38(20.9)$ & $80(22.3)$ & 0.697 & - & - & $31(21.5)$ & $63(22.9)$ & 0.748 & - & - & $7(18.4)$ & $17(20.5)$ & 0.793 & - & - \\
\hline $\begin{array}{l}\text { Cancer and } \\
\text { hematologic } \\
\text { malignancy }\end{array}$ & $96(52.7)$ & $171(47.8)$ & 0.274 & - & - & $77(53.5)$ & $\begin{array}{l}131 \\
(47.6)\end{array}$ & 0.257 & - & - & $19(50.0)$ & $40(48.2)$ & 0.854 & - & - \\
\hline $\begin{array}{l}\text { Chronic kidney } \\
\text { disease }\end{array}$ & $52(28.6)$ & $109(30.4)$ & 0.653 & - & - & $39(27.0)$ & $84(30.5)$ & 0.46 & - & - & $13(34.2)$ & $25(30.1)$ & 0.654 & - & - \\
\hline $\begin{array}{l}\text { Structural abnormality } \\
\text { of the urinary tract }\end{array}$ & $21(11.5)$ & $22(6.1)$ & 0.029 & $\begin{array}{l}2.086 \\
(1.088-4.000)\end{array}$ & 0.027 & $20(13.8)$ & $17(6.2)$ & 0.008 & $\begin{array}{l}2.634 \\
(1.294-5.362)\end{array}$ & 0.008 & $1(2.6)$ & $5(6.0)$ & 0.427 & - & - \\
\hline Hemodialysis & $12(6.6)$ & $33(9.2)$ & 0.297 & - & - & $10(6.9)$ & $20(7.3)$ & 0.902 & - & - & $2(5.3)$ & $13(15.6)$ & 0.109 & - & - \\
\hline \multicolumn{16}{|l|}{$\begin{array}{l}\text { Therapy for } \\
\text { comorbidities, n (\%) }\end{array}$} \\
\hline Abdominal surgery & $90(49.5)$ & $102(28.5)$ & 0 & $\begin{array}{l}2.233 \\
(1.529-3.261)\end{array}$ & 0 & $68(47.2)$ & $72(26.2)$ & 0 & $\begin{array}{l}2.263 \\
(1.464-3.498)\end{array}$ & 0 & $22(57.9)$ & $30(36.1)$ & 0.025 & - & - \\
\hline Steroids & $42(23.1)$ & 75 (20.9) & 0.571 & - & - & $23(16.0)$ & $47(17.1)$ & 0.771 & - & - & $19(50.0)$ & $28(33.7)$ & 0.09 & - & - \\
\hline $\begin{array}{l}\text { Immunosuppressive } \\
\text { agents }\end{array}$ & $30(16.5)$ & $41(11.5)$ & 0.102 & - & - & $17(11.8)$ & $29(10.5)$ & 0.696 & - & - & $13(34.2)$ & $12(14.5)$ & 0.013 & $\begin{array}{l}3.837 \\
(1.397-10.541)\end{array}$ & 0.009 \\
\hline Chemotherapy & $30(16.5)$ & $62(17.3)$ & 0.807 & - & - & $23(16.0)$ & 47 (17.1) & 0.771 & - & - & $7(18.4)$ & $15(18.1)$ & 0.963 & - & - \\
\hline $\begin{array}{l}\text { Urinary } \\
\text { catheterization, } \\
n(\%)\end{array}$ & 75 (41.2) & $145(40.5)$ & 0.875 & - & - & 57 (39.6) & $\begin{array}{l}103 \\
(37.5)\end{array}$ & 0.671 & - & - & $18(47.4)$ & $42(50.6)$ & 0.742 & - & - \\
\hline $\begin{array}{l}\text { Using in situ } \\
\text { device, } n(\%)\end{array}$ & $120(65.9)$ & $190(53.1)$ & 0.004 & - & - & $86(59.7)$ & $\begin{array}{l}132 \\
(48.0)\end{array}$ & 0.023 & - & - & $34(89.5)$ & $58(69.9)$ & 0.02 & $\begin{array}{l}3.807 \\
(1.180-12.276)\end{array}$ & 0.025 \\
\hline $\begin{array}{l}\text { Hemoglobin }(\mathrm{g} / \mathrm{dL}) \text {, } \\
\text { mean }(\mathrm{SD})\end{array}$ & $\begin{array}{l}9.89 \\
(1.97)\end{array}$ & $10.2(2.0)$ & 0.093 & - & - & $10.0(2.0)$ & $10.4(2.1)$ & 0.17 & - & - & $\begin{array}{l}9.37 \\
(1.96)\end{array}$ & $\begin{array}{l}9.63 \\
(1.48)\end{array}$ & 0.143 & - & - \\
\hline $\begin{array}{l}\text { Albumin }(\mathrm{g} / \mathrm{dL}) \\
\text { mean }(\mathrm{SD})\end{array}$ & $\begin{array}{l}2.86 \\
(0.63)\end{array}$ & $\begin{array}{l}3.06 \\
(0.87)\end{array}$ & 0.01 & $\begin{array}{l}0.731 \\
(0.555-0.963)\end{array}$ & 0.026 & $\begin{array}{l}2.86 \\
(0.63)\end{array}$ & $\begin{array}{l}3.13 \\
(0.93)\end{array}$ & 0.002 & $\begin{array}{l}0.668 \\
(0.490-0.911)\end{array}$ & 0.011 & $\begin{array}{l}2.88 \\
(0.63)\end{array}$ & $\begin{array}{l}2.85 \\
(0.55)\end{array}$ & 0.823 & - & - \\
\hline $\begin{array}{l}\text { In-hospital } \\
\text { mortality (\%) }\end{array}$ & 8.2 & 8.9 & 0.786 & - & - & 9 & 7.3 & 0.527 & - & - & 5.3 & 14.5 & 0.144 & - & - \\
\hline \multirow[t]{2}{*}{$\begin{array}{l}\text { Total hospital stay } \\
\text { (days), mean ( } \pm \text { SD) }\end{array}$} & $\begin{array}{l}80.9 \\
(95.0)\end{array}$ & $74.0(110)$ & 0.053 & - & - & $\begin{array}{l}77.5 \\
(101)\end{array}$ & $\begin{array}{l}70.8 \\
(95.0)\end{array}$ & 0.223 & - & - & $\begin{array}{l}93.8 \\
(68.3)\end{array}$ & $86.8(149)$ & 0.04 & - & - \\
\hline & \multicolumn{5}{|c|}{ Hosmer-Lemeshow: $p=0.571$} & \multicolumn{5}{|c|}{ Hosmer-Lemeshow: $p=0.825$} & \multicolumn{5}{|c|}{ Hosmer-Lemeshow: $p=0.677$} \\
\hline
\end{tabular}


the use of vancomycin, gastrointestinal procedures, diabetes mellitus, and acute renal failure could be risk factors for enterococcal bloodstream infections in malignant patients who colonized VRE [15]. As shown in these reports, the risk factors of enterococcal infections, especially VRE, are variable depending on patient background. In addition, the risk factors for VSE infections, which are highly prevalent in Japan, remain unknown. In our study, structural abnormalities of the urinary tract, abdominal surgery, immunosuppressive agent use, male sex, hypoalbuminemia, and the use of in situ devices are the risk factors of VSE infections.

Moreover, Sugiura et al. reported that enterococci are the most common causative pathogens of intraabdominal infections after pancreaticoduodenectomy [16] and recommend accounting for enterococcal infections when selecting antimicrobials for empirical treatment for intra-abdominal infections after abdominal surgery. Furthermore, Kim et al. report that liver transplantations are an independent risk factor for enterococci intra-abdominal infections [17]. A high incidence of enterococcal infection was also found in the current study, and 17 of the 42 liver transplantations performed during 2010-2011 at our hospital were complicated by enterococcal infections (which corresponds to a high complication incidence of $42 \%$ ). In addition, according to an analysis of isolates from intra-abdominal infections after liver transplantations, the isolation frequency of $E$. faecium $(23.7 \%)$ is higher than that of E. faecalis (2.8\%) $(p<0.001)$. Enterococci, particularly E. faecium, are considered important causative pathogens of infections in liver transplantation recipients. In cases in which healthcare-associated infections are suspected after liver transplantation, the intra-abdominal infection complication guidelines of the 2010 Surgical Infection Society and Infectious Diseases Society of America recommend selecting antimicrobial agents that cover enterococci (e.g., ampicillin, piperacillin/tazobactam, vancomycin) to treat infections in patients administered antibiotics that do not cover enterococci, such as cephalosporin; in immunocompromised patients; or patients with valvular heart disease, prosthetic heart valves, or artificial blood vessels [18]. In addition, the resistance to anti-MRSA drugs, especially the increasing prevalence of VRE present in nosocomial infections, has become a major problem in the United States and Europe [5]. Since VRE was first reported as a VanA type-resistant E. faecium in 1988 in the United Kingdom and France, and VanB type-resistant E. faecalis in 1989 [19, 20], its prevalence has been increasing annually; reports from the United States indicate that $62.3-82.6 \%$ of E. faecium isolates detected in nosocomial infections are VRE [9]. In Europe, it is most prevalent in Ireland (44.0\%), followed by Portugal (23.3\%) and Greece (17.1\%) [5, 21]. In China, the prevalence of vancomycin-resistant E. faecium is $2.7 \%$ while that of vancomycin-resistant E. faecalis is $6.5 \%$ [22]; the detection rates in Asia, including Japan, are low [12, 23], and these species were not isolated in the present study.

Interestingly, E. faecalis was identified as the causative pathogen in all cases of enterococcal urinary tract infections in the present study. Enterococci are causative pathogens in complicated urinary tract infections and feature a high isolation frequency [24]. Urine from children with congenital urinary tract disorders shows a high frequency of E. faecalis isolation [25]; in the present study as well, nearly all cases involving $E$. faecalis isolated from the urine were accompanied by congenital and acquired urinary tract disorders. Moreover, the frequency of $E$. faecalis isolation in bacterial cultures from ureteral stents is reportedly high [26]; likewise, in the present study, cases with acquired urinary tract disorders and $E$. faecalis isolation coincided with the presence of artificial devices from procedures such as nephrostomies and stent placements. Many factors related to the onset of urinary tract infection by $E$. faecalis have been reported. For example, enterococcal polysaccharide antigen is reportedly involved in the onset of ascending urinary tract infections since it binds to epithelial cells followed by biofilm formation and/or resistance to phagocytosis by polymorphonuclear leukocytes [27]. On the other hand, fewer reports have examined the pathogenicity of E. faecium affecting the onset of urinary tract infection than those on E. faecalis [10], which may be related to the results of our present clinical study. Structural abnormalities of the urinary tract might be unique compared with the risk factors of VRE infections, mainly caused by E.faecium, indicating that we should closely monitor patients with primary or secondary urinary tract abnormalities, stent placement, and nephrostomy for VSE infections, especially E. faecalis.

The use of immunosuppressive agents was an independent risk factor for $E$. faecium infection. Unlike $E$. faecalis, E. faecium recognizes peptidoglycan differences and has different acid production mechanisms that result in growth rate differences [2]. The recently increasing incidences of collagen diseases, hematologic malignancies, and solid tumors are thought to be related to increases in the number of patients undergoing immunosuppressive therapy; these patients are more likely to receive penicillin and cephalosporin antibiotics. Consequently, increased $E$. faecium levels have been reported with changes in the gut microbiota of the large and small intestines [28].

Our present study identified male sex and hypoalbuminemia as independent risk factors of enterococcal infections. However, these are not specific to enterococcal infections. There have been several reports on the correlation between sex and infection prognosis. Angele et al. 
reported that men have poorer prognosis of septicemia than women, and the main reasons include its correlation with male sex steroids, X-chromosome mosaicism, etc. [29]. Hypoalbuminemia is also a known risk factor related to the onset of and mortality caused by various infections [30].

The mortality rates of enterococcal infections including VRE are high (25-50\%) since they often develop in compromised hosts [31-37]. Enterococci are not highly pathogenic per se, and their survival rates mainly depend on underlying disease severity. However, the mortality rates of enterococcal infections in the present study $(8.2 \%)$ were low compared to those of previous reports. The likely reasons for this are as follows: VRE was not detected in this study; anti-MRSA agents such as vancomycin were immediately administered against $E$. faecium, and treatment with appropriate antimicrobial agents was administered during the early stages of onset; and nearly all subjects were inpatients undergoing careful pathologic monitoring. Patients who contracted $E$. faecium infections from carriers had significantly longer hospital stays on univariate analysis. This is probably because of the increased condition severity of the patients with E. faecium infections as well as a high degree of drug resistance that necessitated long-term antimicrobial agent use [35-37].

\section{Conclusions}

This study revealed the independent risk factors for $E$. faecalis and faecium infections. Significant risk factors for infection on multivariate analysis were structural abnormalities of the urinary tract, abdominal surgery, immunosuppressive agent use, in situ device use, male sex, and hypoalbuminemia. There was a significant correlation between liver transplantations and infections with E. faecium compared to E. faecalis. In cases complicated by bacteremia or intra-abdominal infections, enterococci are pathogenic microorganisms with a high mortality rate that must be handled carefully. Studies on risk factors for the onset of enterococcal infections provide useful information for clinicians, enabling improved prognosis, reduced hospitalization, and the proper use of antimicrobial agents through early treatment intervention. Nevertheless, additional prospective studies are necessary to confirm the present findings.

\section{Consent}

Written informed consent was obtained from the patient for the publication of this report and any accompanying images.

\footnotetext{
Abbreviations

E. faecalis: Enterococcus faecalis; E. faecium: Enterococcus faecium; SPSS: Statistical Package for the Social Sciences; SD: Standard deviation; OR: Odds ratio; Cl: Confidence interval.
}

Competing interests

The authors declare no competing interests.

\section{Authors' contributions}

TK and SN designed the study, collected and analyzed the clinical data, and wrote the manuscript. NI, KO, and TT collected the clinical data. TM, KI, KY, NK, and SK interpreted the results and reviewed the final draft of the manuscript. All authors read and revised the final manuscript for critical intellectual content.

\section{Acknowledgements}

We thank the staff at the Microbiology laboratory, Nagasaki University Hospital, for consecutively including the cases and collecting the data. We also express our appreciation to all of our study participants.

\section{Author details}

'Department of Respiratory Diseases, Nagasaki University Graduate School of Biomedical Sciences, Nagasaki, Japan. ${ }^{2}$ Department of Molecular Microbiology and Immunology, Nagasaki University Graduate School of Biomedical Sciences, Nagasaki, Japan. ${ }^{3}$ Department of Laboratory Medicine, Nagasaki University Hospital, Nagasaki, Japan. ${ }^{4}$ Department of Molecular and Internal Medicine, Hiroshima University, Graduate School of Biomedical Sciences, Hiroshima, Japan. ${ }^{5}$ Department of Chemotherapy and Mycoses, National Institute of Infectious Diseases, 1-23-1 Toyama, Shinjuku-ku, Tokyo 162-8640, Japan.

Received: 15 March 2015 Accepted: 5 October 2015

Published online: 16 October 2015

\section{References}

1. Arias CA, Murray BE. Emergence and management of drug-resistant enterococcal infections. Expert Rev Anti Infect Ther. 2008;6:637-55.

2. Murray BE. The life and times of the Enterococcus. Clin Microbiol Rev. 1990:3:46-65.

3. Franz CM, Huch M, Abriouel H, Holzapfel W, Galvez A. Enterococci as probiotics and their implications in food safety. Int J Food Microbiol. 2011;151:125-40

4. Cheong HS, Kang C-I, Lee JA, Moon SY, Joung MK, Chung DR, et al. Clinical significance and outcome of nosocomial acquisition of spontaneous bacterial peritonitis in patients with liver cirrhosis. Clin Infect Dis. 2009;48:1230-6.

5. Orsi GB, Ciorba V. Vancomycin-resistant enterococci healthcare infections. Ann lg. 2013;25:485-92.

6. Mikulska M, Del Bono V, Prinapori R, Boni L, Raiola AM, Gualandi F, et al. Risk factors for enterococcal bacteremia in allogeneic hematopoietic stem cell transplant recipients. Transpl Infect Dis. 2010;12:505-12.

7. Weinstock DM, Conlon M, lovino C, Aubrey T, Gudiol C, Riedel E, et al. Colonization, bloodstream infection, and mortality caused by vancomycinresistant enterococcus early after allogeneic hematopoietic stem cell transplant. Biol Blood Marrow Transplant. 2007;13:615-21.

8. Vydra J, Shanley RM, George I, Ustun C, Smith AR, Weisdorf DJ, et al. Enterococcal bacteremia is associated with increased risk of mortality in recipients of allogeneic hematopoietic stem cell transplantation. Clin Infect Dis. 2012;55:764-70.

9. Sievert DM, Ricks P, Edwards JR, Schneider A, Patel J, Srinivasan A, et al. Antimicrobial-resistant pathogens associated with healthcare-associated infections: summary of data reported to the National Healthcare Safety Network at the Centers for Disease Control and Prevention, 2009-2010. Infect Control Hosp Epidemiol. 2013;34:1-14.

10. Arias CA, Murray BE. The rise of the enterococcus: beyond vancomycin resistance. Nat Rev Microbiol. 2012;10:266-78.

11. Clinical and Laboratory Standards Institute. Performance standards for antimicrobial susceptibility testing; Approved standard M100-S22. Wayne, PA: Clinical and Laboratory Standards Institute; 2009.

12. Yoshida I, Yamaguchi T, Kudo R, Fuji R, Takahashi C, Oota R, et al. Antimicrobial susceptibility of clinical isolates of aerobic gram-positive cocci and anaerobic bacteria in 2008. Jpn J Antibiot. 2012;65:49-72.

13. Kim YJ, Kim SI, Kim YR, Lee JY, Park YJ, Kang MW. Risk factors for vancomycinresistant enterococci infection and mortality in colonized patients on intensive care unit admission. Am J Infect Contr. 2012;40:1018-9. 
14. Olivgeris MP, Drougka E, Fligou F, Kolonitsiou F, Liakopoulos A, Dodou V, et al. Risk factors for enterococcal infection and colonization by vancomycinresistant enterococci in critically ill patients. Infection. 2014;42:1013-22.

15. Zaas AK, Song X, Tucker P, Perl TM. Risk factors for development of vancomycin-resistant enterococcal bloodstream infection in patients with cancer who are colonized with vancomycin-resistant enterococci. Clin Infect Dis. 2002;35:1139-46.

16. Sugiura T, Uesaka K, Ohmagari N, Kanemoto H, Mizuno T. Risk factor of surgical site infection after pancreaticoduodenectomy. World J Surg. 2012:36:2888-94.

17. Kim YJ, Kim SI, Wie SH, Kim YR, Hur JA, Choi JY, et al. Infectious complications in living-donor liver transplant recipients: a 9-year singlecenter experience. Transpl Infect Dis. 2008;10:316e24.

18. Solomkin JS, Mazuski JE, Bradley JS, Rodvold KA, Goldstein EJ, Baron EJ, et al. Diagnosis and management of complicated intra-abdominal infection in adults and children: guidelines by the Surgical Infection Society and the Infectious Diseases Society of America. Clin Infect Dis. 2010;50:133e64.

19. Leclercq R, Derlot E, Duval J, Courvalin P. Plasmid-mediated resistance to vancomycin and teicoplanin in Enterococcus faecium. N Engl J Med. 1988;319:157-61

20. Sahm DF, Kissinger J, Gilmore MS, Murray PR, Mulder R, Solliday J, et al. In vitro susceptibility studies of vancomycin-resistant Enterococcus faecalis. Antimicrob Agents Chemother. 1989;33:1588-91.

21. EARS-Net. European Antimicrobial Resistance Surveillance Network (EARSNet). Available at: http://ecdc.europa.eu/en/healthtopics/ antimicrobial_resistance/database/Pages/table_reports.aspx EARS-Net/ database/Pages/database.aspx.

22. Jia XQ, Pang F, Chen JZ, Jiang LX. Prevalence and clinical distribution of multidrug-resistant bacteria (3537 isolates) in a tertiary Chinese hospital (January 2012-December 2013). Pathol Biol (Paris). 2015;63:21-3.

23. Muratani T, Matsumoto T. Bacterial resistance to antimicrobials in urinary isolates. Int J Antimicrob Agents. 2004;24:S28-31.

24. Spoorenberg V, Prins JM, Stobberingh EE, Hulscher ME, Geerlings SE. Adequacy of an evidence-based treatment guideline for complicated urinary tract infections in the Netherlands and the effectiveness of guideline adherence. Eur J Clin Microbiol Infect Dis. 2013;32:1545-56.

25. Bitsori M, Maraki S, Raissaki M, Bakantaki A, Galanakis E. Community-acquired enterococcal urinary tract infections. Pediatr Nephrol. 2005;20:1583-6.

26. Ben-Meir D, Golan S, Ehrlich Y, Livne PM. Characteristics and clinical significance of bacterial colonization of ureteral double-J stents in children. J Pediat Urol. 2009;5:355-8.

27. Singh KV, Lewis RJ, Murray B. Importance of the epa locus of Enterococcus faecalis OG1RF in a mouse model of ascending urinary tract infection. J Infect Dis. 2009;200:417-20.

28. Kristich CJ, Rice LB, Arias CA. Enterococcal infection-Treatment and antibiotic resistance. In: Gilmore MS, Clewell DB, Ike Y, Shankar N, editors. Enterococci: From commensals to leading causes of drug resistant infection Internet]. Boston: Massachusetts Eye and Ear Infirmary; 2014. p. 1-48

29. Angele MK, Pratschke S, Hubbard WJ, Chaudry $\mathrm{H}$. Gender differences in sepsis Cardiovascular and immunological aspects. Virulence. 2014;5:1,12-19.

30. Gatta A, Verardo A, Bolognesi M. Hypoalbuminemia. Intern Emerg Med. 2012;7 suppl 3:S193-9.

31. McBride SJ, Upton A, Roberts SA. Clinical characteristics and outcomes of patients with vancomycin-susceptible Enterococcus faecalis and Enterococcus faecium bacteraemia - a five-year retrospective review. Eur J Clin Microbiol Infect Dis. 2010;29:107-14.

32. Caballero-Granado FJ, Becerril B, Cuberos L, Bernabeu M, Cisneros JM, Pachon J. Attributable mortality rate and duration of hospital stay associated with enterococcal bacteremia. Clin Infect Dis. 2001:32:587-94.

33. Bhavnani SM, Drake JA, Forrest A, Deinhart JA, Jones RN, Biedenbach DJ, et al. A nationwide, multicenter, case-control study comparing risk factors, treatment, and outcome for vancomycin-resistant and -susceptible enterococcal bacteremia. Diagn Microbiol Infect Dis. 2000;36:145-58

34. Edmond MB, Ober JF, Weinbaum DL, Pfaller MA, Hwang T, Sanford MD, et al. Vancomycin-resistant Enterococcus faecium bacteremia: risk factors for infection. Clin Infect Dis. 1995:20:1126-33.

35. DiazGranados CA, Zimmer SM, Klein M, Jernigan JA. Comparison of mortality associated with vancomycin-resistant and vancomycin-susceptible enterococcal bloodstream infections: a meta-analysis. Clin Infect Dis. 2005:41:327-33.
36. Carmeli Y, Eliopoulos G, Mozaffari E, Samore M. Health and economic outcomes of vancomycin-resistant enterococci. Arch Intern Med. 2002;162:2223-8.

37. Noskin GA, Peterson LR, Warren JR. Enterococcus faecium and enterococcus faecalis bacteremia: acquisition and outcome. Clin Infect Dis. 1995;20:296-301.

\section{Submit your next manuscript to BioMed Central and take full advantage of:}

- Convenient online submission

- Thorough peer review

- No space constraints or color figure charges

- Immediate publication on acceptance

- Inclusion in PubMed, CAS, Scopus and Google Scholar

- Research which is freely available for redistribution 